\title{
Teacher's didactical moves in the technology classroom
}

\author{
Maria Svensson $^{1}$ - Gerd Johansen ${ }^{2}$
}

Accepted: 8 November 2017/Published online: 24 November 2017

(C) The Author(s) 2017. This article is an open access publication

\begin{abstract}
In the technology classroom, practical problem-solving activities require interaction between teacher and students. To explore these interactions, we use Joint Action Theory of Didactics (JATD). Joint actions occur within a didactical system where teacher, students and content are understood as an undividable whole. Of particular interest is how the teacher interacts with students and the milieu: the objects, processes and concepts needed to solve the problem. We regard this combination of the students and milieu (the student-milieu) as a unit with which the teacher interacts. Creating joint action relies on joint attention, joint affordances and common ground. Moreover, we use the concept didactical moves to describe how the teacher facilitates joint action to create opportunities for students to interact with the milieu. We analyse video-recorded observations of a group of students, aged 14, who are working with a practical problem, building a bridge model. Our results indicate that the teacher's didactical moves attempt to achieve an integration of students' procedural and conceptual understanding. However, the teacher overlooks the need to establish common ground related to certain aspects of the milieu, and there are few joint affordances in relation to central concepts among the students. We argue that JATD is appropriate when analysing and reflecting on practical problem solving and teachers' strategies for handling interactions with the student-milieu.
\end{abstract}

Keywords Joint action theory of didactics · Practical problem-solving · Technology education · Procedural knowledge · Conceptual knowledge

Maria Svensson

maria.svensson@ped.gu.se

Gerd Johansen

gerd.johansen@nmbu.no

1 Department of Pedagogical, Curricular and Professional Studies, University of Gothenburg, Gothenburg, Sweden

2 Faculty of Science and Technology, Norwegian University of Life Sciences, Ås, Norway 


\section{Introduction}

Practical activities are an integral part of technology education in school and these activities are usually collaborative, where a group of students works with technological processes: analysing, synthesising and evaluating a problem (de Vries 2005). The teacher plays an important role in engaging students and helping them to be attentive to the content in focus, in order to develop their knowledge of the subject. Practical technology activities simultaneously require both conceptual and procedural knowledge. In this study, the aim is to identify teachers' interactions with students (talking, gesturing and handling objects) as part of the implementation of teachers' strategies for facilitating students' learning of content.

There is a lack of empirical studies on practical problem-solving activities in technology education and what these activities require of the teacher and students (e.g. Jones et al. 2011). McCormick (2004) argues that the teacher's communication with students during their work with practical problem solving is highly influential with regard to students' progress and the decisions they make, and thus affects the learning outcome. Our contribution is an empirical analysis of a teacher's interactions with a group of students when they are building a bridge model: how the teacher and the students jointly display attention, common ground and an understanding of the affordances of conceptual and procedural aspects of content. The teacher is an important role model for the students with regard to how to work with technology knowledge in practical problem solving. We explore the teacher's interactions with a group of students using Joint Action Theory of Didactics (JATD) (e.g. Brousseau 1997; Schoenfeld 2012). JATD stems from a French didactic tradition and it attempts to deal with the socio-historical culture of school, the relationship(s) teaching-learning-knowledge and the situated practice in classrooms (Venturini and Amade-Escot 2014). JATD is widely used within mathematics and science education (see e.g. Chevallard and Sensevy 2014), and thus interesting to apply as a framework within technology education. JATD enables descriptions and "it attempts to recognise the fundamental logic" of what goes on between the teacher and the students in an educational situation (Sensevy 2012, p. 513). Furthermore, Sensevy (2012) argues that JATD might also function as a starting point for prescriptions about educational situations, and thus, JATD provides us with an opportunity to discuss possible implications of the educational situations. In this study, it is of particular interest how the teacher interacts with students and the milieu. The milieu is "the actual material and symbolic structure of the problem at stake, which one has to deal with in order to solve this problem" (Sensevy 2015, p. 639). This means that the milieu includes the materials the students use to build the bridge model, in addition to the concepts and procedures they need for thinking, speaking and building. We regard the combination of the students and milieu (the student-milieu) as a unit with which the teacher interacts.

Our aim is to identify teachers' interactions with the student-milieu through talking, gesturing and handling objects, as part of the implementation of strategies for students' learning of content. Our research question is:

How does the teacher interact with the student-milieu to facilitate the learning of school technology content?

To explore this question, we analysed $3 \mathrm{~h}$ of video material from a Swedish technology classroom. The technology teacher is experienced and the students, aged 14, have had technology once a week for nearly a year. 


\section{Theoretical framework}

\section{Teachers' interactions with student-milieu}

A cornerstone in JATD is that teachers' actions (teaching) are fundamentally interlinked with students' actions (learning) as well as the structure and function of knowledge. The didactical triangle may be used as a frame for studying teaching-learning-knowledge situations. The didactical triangle can be used to describe what happens when content is taught and learned. Although there are different versions of the triangle, we choose to build on Schoenfeld's (2012) version of the triangle. He states that the didactical triangle has to be seen as a unified didactical system. This means that there is interdependency between teacher, students and content, i.e. a triangular relation, where one cannot exist without the others.

"Here, one sees the student interacting with a particular (mathematical)/(technological) ${ }^{1}$ milieu, which has its own mathematical (technological) structure... The student-milieu interaction is "adidactic," in that the milieu constrains the student(s) mathematically (technologically) by virtue of its own structure. The teacher has selected/established the rules of the game ${ }^{2}$ and then the didactical moves made by the teacher interact with the student(s) and the student-milieu system." (ibid. p. 590)

A vital part of what a teacher does is to create a milieu for the students. The milieu is the physical objects the students use when working practically, in addition to texts, the norms for argumentation and talk (Laborde 2015). In other words, the milieu is the students' 'knowledge surroundings'. The students interact with the milieu and the teacher interacts with the student-milieu in joint action (Brousseau 1997). Teachers' and students' actions are individual, but the actions contribute to creating whole situations. For example, the teacher's actions are different from students' actions even though all actions are part of the same situation. Joint attention together with common ground and joint affordances are concepts used to describe joint action (Sensevy 2011, 2012).

- Joint attention is the sharing of attention to what is required in the situation, such as objects, processes and concepts.

- Common ground refers to the shared preconceptions and the conceptions that develop, which make the communication of objects, processes and concepts possible in the practical problem situation.

- Joint affordances means that participants in a given environment recognise the same affordances - they see the same possibilities and alternatives in regard to the objects, processes and concepts.

Joint attention, common ground and joint affordances are interconnected but can be analytically divided. We use the concept 'didactical moves' to denote teachers' interactions with students and the milieu, which are the actions that establish joint action with the student-milieu. This way of applying didactical moves deviates somewhat from Schoenfeld (2012), where we in particular see didactical moves concerning the student-milieu system, as our interest is related to technology content and not to teacher's interaction with students per ce. We put emphasis on students' influence on the didactical system and thereby their influence on teachers' interactions in practical explorative learning situations.

\footnotetext{
1 This article author's addendum.

2 JATD builds on Wittgensteins notion of game (Wittgenstein 1953).
} 


\section{Technology knowledge}

Technology knowledge, as described by Ryle (1949/2000), involves both thinking and doing, without separating mental and physical processes, and knowledge is expressed when acting. This description highlights the strong connection between student and milieu. In technology education, the milieu could be described as rich as it consists of hands-on activities, consumable materials, objects and concepts, all of which are important for the teacher to take account of when teaching practical problem solving.

A philosophical point of view that has had an impact on the development of technology education derives from Mitcham's (1994) conceptualisations of technology as objects, knowledge, actions and volition. Mitcham argues that technology as an activity integrates knowledge and volition, and brings an artefact into existence or into use. An activity is thus a manifestation of technology. Activity in technology includes processes such as: inventing, designing, crafting, maintaining, manufacturing, working and operating. In schools, technology activities are often presented as practical problem-solving activities where students develop ideas and technological solutions collaboratively. This approach has emerged as central to technology education in providing contexts for learning that reflect the authentic process of developing technological solutions (Blomdahl and Rogala 2008; Ginestié 2002; Hill 1998).

A practical problem-solving activity involves both thinking and doing. Theoretically this might be understood in several ways (e.g. Hansson 2013; Ropohl 1997; Vincenti 1990). We choose to build on McCormick (2004) which states that "basic types of technology knowledge: procedural and conceptual" (p. 24). Moreover it is important to be aware of the context dependency of all technology knowledge. For example, when building a bridge, stability is a central concept. However, stability depends on, for example, material properties, placement and load. Procedural knowledge and skills are likewise context dependent, e.g. how to join specific materials, appropriate tools for materials and the order of the constructional steps. This context dependency implies that it is important to move between different contexts rather than focusing on abstractions (McCormick 2004).

- Procedural knowledge is described as know-how-to-do-it knowledge, being able to take on and solve a problem in a practical way (McCormick 2006). It is knowledge about processes, or knowledge transmitted through processes of making things, including creative processes and real-life technological problem solving (Hill 1998; Pirttimaa et al. 2015). Solving technological problems also includes handling objects, tools and machines, which requires practical skills regarding how, when and why we use them. De Vries (2005) also includes non-verbal knowledge in procedural knowledge, a sense of what is right or wrong, e.g. the plumber's sense of how hard a pipe must be tightened.

- Conceptual knowledge is described as understanding how things are connected and related to each other, and being able to think out solutions and link knowledge from different areas (McCormick 2006).

Procedural knowledge and conceptual knowledge are included in practical problem solving and constitute the students' knowledge surroundings. When studying a practical problemsolving activity, it is necessary to study procedural and conceptual knowledge both separately and together in order to grasp the character of technology as a knowledge area. As Esjeholm and Bungum (2013) say, it is important to understand technology knowledge as an integration of both conceptual and procedural knowledge: 
"technology knowledge is not the sum of distinct categories of knowledge that are either conceptual or procedural, but forms an amalgamation of insights and skills adjusted to the context at hand and immersed in technology activity." (p. 677)

A practical problem-solving activity in technology education is a didactical system where the teacher, students and content meet and are mutually dependent on each other. However, the teacher's interactions with the student-milieu, the didactical moves, are of special interest in this study, where didactical moves are the teachers' part of the joint actions. The joint actions in practical problem-solving activities imply teachers and students' joint attention to the material in hand, the process for developing a solution and the requirements of the solution. Joint affordances in these practical situations could be the constraints and possibilities of using tools. Common ground relates to preconceptions, such as understanding of technological principles and material properties.

\section{Context and method}

The data used in our study is derived from technology lessons where teacher and students interact with the goal of building a bridge model. Technology is described in the Swedish national curriculum as a subject that aims to develop students' technical skills and their technological awareness so that they can orient themselves and act in a technology-intensive world. The teaching should help students to develop an interest in technology and the ability to take on technical challenges in a conscious and innovative way (Skolverket 2011).

\section{Setting the scene}

The class consists of 18 students, aged 14, who have taken the subject technology during the spring semester, one lesson a week, 60 min per lesson. The three lessons that were video recorded were not modified in any way, but may be viewed as a glimpse into authentic technology education in Swedish compulsory school. The teacher has been a teacher for 25 years and she teaches science, mathematics and technology. She presents the project that the class is working with as the "Bridge Project". The aim of the project is to build a stable model of a bridge. The "bridge specifications" say that the bridge model should hold a weight of 5 kilos, and be 40 centimetres long, 15 centimetres high, 11 centimetres wide and with a span of 15 centimetres. Each group receives the same material to build their model with: a number of wooden lolly sticks (50 pcs), two round sticks, a two-metre-long string and glue to melt. The teacher inspires the students by providing pictures of different bridge constructions and buildings with lattice work. The students are also encouraged to use their knowledge from earlier lessons about stable constructions, such as triangles.

The students are working together in groups of three to four students, where they are expected to agree on what the model of the bridge should look like and to document it in a sketch. They are to use the sketch as a template for the construction and evaluate the result at the end of the project. 


\section{Data collection}

The data consists of three video-recorded lessons, with one video camera focusing on the teacher, one focusing on the class as a whole and the last camera focusing on one group. In this study, video data from the group is analysed. The first author collected and transcribed the data.

In the first recorded lesson, the students started to build a model of a bridge using the bridge specifications. Between the first and the second recorded lesson, there were two lessons where the groups continued their work with the bridge model. The last visit to the class was when the bridge model was tested in terms of stability and strength (see Fig. 1).

Of the three recorded lessons, the first lesson is the one that is used in the following analysis, as it is important what didactical moves the teacher chooses in this starting phase in order to set the students on the right track. The teacher starts the first lesson with an introduction to remind the students about bridge specifications and after that the group starts to work practically. We have chosen to follow one group. All three students in this group, two boys and one girl, had agreed to be recorded, and they take the initiative in talking to the teacher during the lesson.

We have selected excerpts that highlight teacher interactions with the student-milieu. The excerpts presented in the results are numbered from 1 to 4, where Excerpt 1 is the first, beginning $13.43 \mathrm{~min}$ into the lesson (see Table 1). In the excerpt, the three students in the group are named Student A, Student B and Student C. We use [...] in the excerpt when we make interpretations and (...) when we describe students' actions. Photos used in this article are approved for use in research.

\section{Method of analysis}

Initially, we identified two strands, technology knowledge and interactions between teacher and students. The theoretical framework presented earlier (JATD) is an outcome of our elaboration of the two strands. This theoretical framework is used in a directed content analysis (e.g. Hsieh and Shannon 2005). Content analysis is defined as a research method for the subjective interpretation of the content of text data through the systematic classification process of coding and identifying themes or patterns. In a directed content analysis the goal is: "...to validate or extend conceptually a theoretical framework or theory" (Hsieh and Shannon 2005, p. 1218). The directed content analysis enables us to: (1) code technology content into procedural and conceptual knowledge, and (2) use joint action

Fig. 1 The last lesson where the bridge model is tested with a 5-kilo weight; the bridge in the picture fails the test

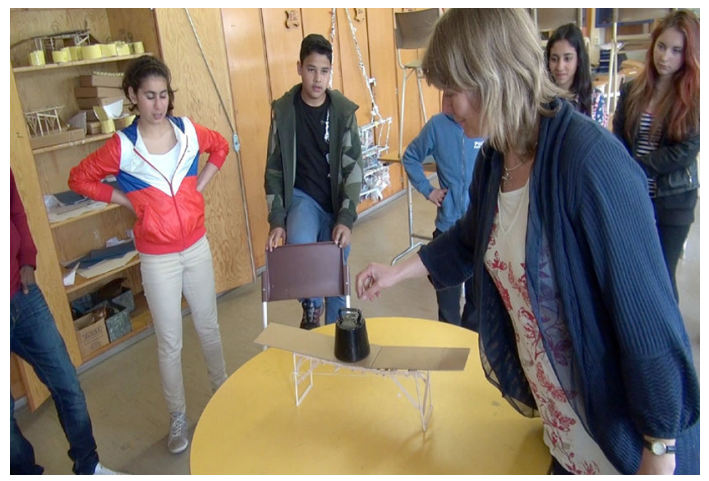


Table 1 Excerpt descriptions

\begin{tabular}{llll}
\hline Excerpt & Time & Teacher: main interaction & $\begin{array}{l}\text { Identified } \\
\text { didactical moves }\end{array}$ \\
\hline 1 & 13.43 & $\begin{array}{c}\text { Examines how work is progressing-lolly stick properties } \\
\text { Examines students' knowledge about stability_lolly sticks and } \\
\text { stability; triangles, direction of load and stability }\end{array}$ & $\begin{array}{l}\text { Joint attention } \\
\text { Common ground }\end{array}$ \\
3 & 28.32 & $\begin{array}{l}\text { Discusses limitations and possibilities—lolly sticks as the building } \\
\text { material for the bridge model }\end{array}$ & Joint affordances \\
4 & 34.00 & $\begin{array}{l}\text { Finds out how the work has progressed—using triangles to build } \\
\text { stable bridge pillars }\end{array}$ & Joint attention \\
\hline
\end{tabular}

(joint attention, common ground and joint affordances) to identify connections between procedural and conceptual knowledge in teaching. Joint action is made visible when teachers and students interact in a practical problem-solving situation through communication, gestures and use of materials.

The first stage of the analysis was to look through the video recordings from the three lessons several times to identify sequences where students in the group in focus, together with the teacher, discussed the design of the bridge model. This first stage of analysis was conducted jointly by both authors. In the second stage, we used technology knowledge and joint action as a lens to look at data, in an iterative process between the authors. The tentative coding schemes where presented and discussed with a science-technology research group, which helped strengthen the scheme. This resulted in us revisiting the original recordings and adjusted the codes accordingly. In the third stage in the analysis, we described what the teacher did and said to establish joint action by asking ourselves questions such as: How does the teacher seek to establish common ground regarding preconceptions, concepts, procedural knowledge and skills? How does the teacher seek to establish joint attention and joint affordances?

\section{How does the teacher interact with the student-milieu to facilitate learning of technology knowledge?}

The concept didactical moves denotes teachers' actions for establishing joint action with the student-milieu. The categories presented below overlap to some extent as they are joint actions concerning the same objects, processes and concepts and are thereby open to different interpretations.

In order to allow a better understanding of the excerpts, we supplement them with pictures from the video recordings, as well as with pictures taken afterwards that show parts of the practical work that it is difficult to see from the video material.

\section{Didactical moves: joint attention}

According to Sensevy (2011, p. 66), "the first condition for two (or x) persons to be able to perform a joint action is to attend to the same objects. Performing a joint action needs a specific type of attention, joint attention, in which attending to the same object means at the same time being aware of the other's attention". The teacher's didactical moves require 
that both the teacher and the students focus their attention on the physical and/or conceptual objects they are dealing with, but also 'listen in' on each other to enable apt interpretation of the other's actions. The teacher's didactical moves directed towards establishing joint attention are to act and speak so that the knowledge at stake and the objects (e.g. lolly sticks) are the focus of the students' attention (Sensevy 2012). However, in teacher-student interaction, students may also set the agenda for what to focus attention on-then the didactical move becomes how the teacher follows up the student's input.

The students start to build and after a while the teacher walks around between the groups and approaches them with questions, and sometimes the students call for the teacher's attention. The students in the group are discussing the bridge specifications. We interpret these excerpts as indicating that the students are trying to establish joint attention in relation to the objects, showing each other ideas about how to build the bridge model, using gestures and the material in front of them (see 1.3 and 1.4 in Excerpt 1). Student's procedural knowledge, about know-how-to-do-it, is important in these discussions.

\section{Lolly stick properties}

In this excerpt, the teacher approaches the three students when they are involved in a discussion about how to put the material (lolly sticks) together. Two of the students are showing each other how they want to use the lolly sticks. The teacher starts out with an open question: "How's it going?" Only Student B reacts to this question: "Badly". The two other students continue their discussion. The teacher rephrases B's statement into a question. $\mathrm{B}$ answers and $\mathrm{A}$ and $\mathrm{C}$ continue their discussion. The teacher stands and listens for a while and then changes the topic: "How are the lolly sticks strongest? In which direction?"

\subsection{Teacher: How's it going?}

1.2. Student B: Badly

1.3. Student A: No, we... should not have it like this (using the lolly sticks to show what she means, assembling the lolly sticks as in Fig. 2a)

1.4. Student C: Then like this... under the... (wants to assemble the lolly sticks as in Fig. 2b)

1.5. Teacher: Is it going badly?

1.6. Student $\mathrm{C}: \ldots$ and then like this

1.7. Student B: I don't know what she's doing [referring to Student A]

[...]

1.16. Teacher: How are the lolly sticks strongest? In which direction?

Fig. 2 Reconstructed photo. Constructions of triangles where the ends of each lolly stick do not overlap in a consistent way (a) and where the ends of each lolly stick overlap in a consistent way, with each stick having one end over and one end under the adjacent sticks (b)
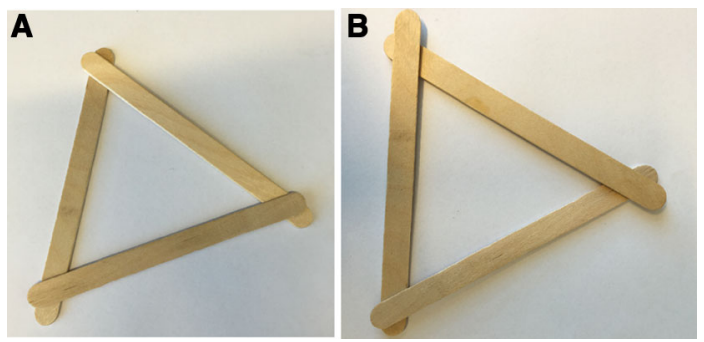
Teacher makes a didactical move through the question: "How are the lolly sticks strongest? In which direction?"; this creates joint attention as A and C redirect attention towards the teacher, as does B. The attention is on the lolly sticks and their affordances. In the beginning of the excerpt, Students $\mathrm{A}$ and $\mathrm{C}$ are talking about how to put the lolly sticks together (procedural knowledge) then the teacher redirects attention to technological conceptual knowledge of the lolly sticks. In making this didactical move, the teacher makes the group aware of what may be important knowledge for solving the problem.

\section{Using triangles to build stable bridge pillars}

Another example of the teacher's didactical moves to establish joint attention is identified when the teacher comes back to the group later to check on their work. The group have the bridge path ready (see Fig. 3) and are discussing how to continue building the bridge pillars. They show each other how they want to use the lolly sticks for the bridge pillars by laying them out on the table. They are focused on doing (procedural knowledge) and on how to use the triangle form (conceptual knowledge) when the teacher asks them a question "Have you counted that there is enough for the legs of the bridge [bridge pillars]" to focus their attention on how many lolly sticks there are left. In the excerpt, we see that Student A responds to the teacher's question but continues showing how to build the bridge pillars and Students B and C are also focused on the construction. The teacher persists in her question and in the end the teacher addresses the question directly to Student B, at which point the students start to count the lolly sticks.

4.29 Teacher: Have you counted that there is enough for the legs of the bridge [bridge pillars]

4.30 Student A: Yes

4.31 Teacher: Count that there is enough for the legs first. What are you doing now?

4.32 Student A: Yes I will...

[...]

4.35 Teacher: Have you put...

4.36 Student B: No. Leave it as it is (referring to how to use lolly sticks in the bridge pillar, not agreeing with Students A and C)

4.37 Teacher: A question... have you put aside the ones for the legs [bridge pillars].

Fig. 3 The bridge path is ready and the students have lolly sticks in front of them that they use when explaining how to build the bridge pillars

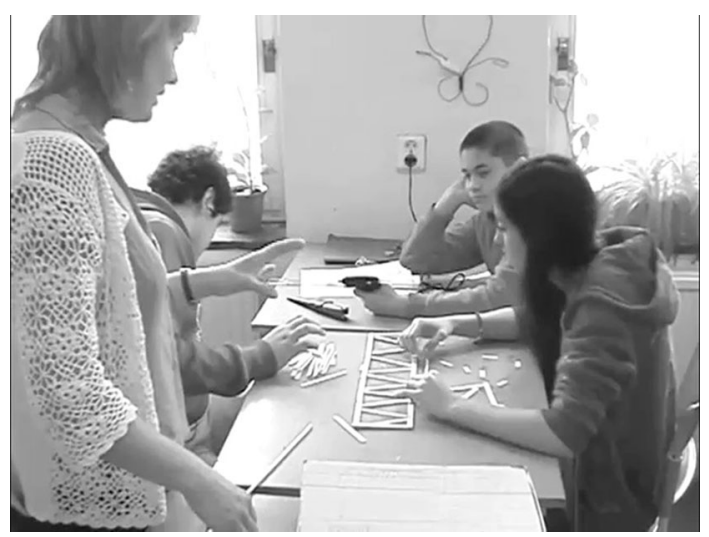


4.38 Student C: Look, this is what you do...

4.39 Teacher: Student B, have you put aside the ones for the legs [bridge pillars]?

4.40 Student B: No

4.41 Teacher: Do that, so you can use the rest to stabilise [the bridge]

Students' joint attention is on how to construct stable bridge pillars using triangles (procedural and conceptual knowledge) but the teacher wants to redirect their attention to also create a joint attention concerning the limited amount of material. Awareness about material availability in relation to the process of building a model is part of procedural knowledge.

In these two excerpts, we can see that the teacher is redirecting the students' attention. The teacher tries to make them aware of knowledge that is important for solving the problem by establishing joint attention on conceptual knowledge as well as procedural knowledge. In the first excerpt, the teacher tries to redirect the students' attention from focusing on how to join the lolly sticks and to build a construction (procedural) to the properties of the lolly stick (conceptual). In the second excerpt, the teacher redirects attention from construction (procedural and conceptual knowledge) to the resources (the number of lolly sticks) that are available in this specific situation.

\section{Didactical moves: common ground}

Common ground, as a description of joint action, consists of all those things that are (to be) taken for granted. In the present situation, knowledge about how to handle the glue gun is taken for granted. Handling tools and machines is described by McCormick (2004) as a practical skill included in technological knowledge. The triangle as a stable form when constructing is an example of conceptual knowledge that the students are using in the activity, a preconception that they discuss in the group. There is an established common ground regarding this. There are also elements in the present situation that are not yet taken for granted and could provide "new habits of thoughts" (Sensevy 2011, p. 65). In relation to those things that are not yet taken for granted, the teacher has an important role in helping the students to establish new common ground. New habits of thoughts in practical problem-solving situations concern objects and processes as well as concepts. The teacher's didactical moves are directed towards establishing common ground with regard to: (1) shared preconceptions and (2) concepts and processes that are to be learned.

\section{Lolly sticks and stability}

When the teacher approaches the group during their negotiation about how to put together the lolly sticks and the bridge specifications, she asks a question about the lolly sticks and how they should be loaded to withstand most pressure. We interpret this as a didactical move to establish an awareness of common ground about the concepts related to stability. After the teacher has asked the question about how the lolly sticks are strongest, Student B shows what he thinks and Student A agrees but hesitates.

2.1. Teacher: How are the lolly sticks strongest? In which direction? This way or lying on the flat side?

2. 2. Student B: Like this (puts a lolly stick flat on the bench, see Fig. 5b)

2.3. Student A: Yes, like that...or

2.4. Teacher: I am not answering. Discuss it 


\subsection{Student B: Oh no}

In the excerpt, the teacher's didactical move is directed towards establishing common ground about stability in a lolly stick (conceptual knowledge) but we also see that the teacher wants the students to establish common ground by themselves, as she explicitly asks them to discuss the matter (2.4). Student B indicates that they do not think it is a good idea (see 2.5). We interpret this as the teacher making a didactical move by repeatedly examining whether the specific content has been established as common in the group.

\section{Triangles, direction of load and stability}

In Fig. 4a, we see that the group are discussing the construction by showing each other triangles using their hands. The teacher asks them about the stability of triangles, "In which direction do you load the triangle? In which way is the triangle strong?". The teacher's didactical move in this situation is directed towards establishing common ground about the stability of triangles (conceptual knowledge). The teacher demonstrates this with her hands, see Fig. 4b, c.

2.12. Teacher: In which direction do you load the triangle? In which way is the triangle strong?

2.13. Student A: Like this (showing a triangle form with her hands, Fig. 4a)

[...]

2.14. Teacher: Like this (puts her hand on top of the triangle (Fig. 4b) or (puts her hand on one of the corners (Fig. 4c))... now I have helped you a lot now I will leave before I say too much.

In this situation, we also see that the teacher, after providing some crucial input about material properties (conceptual knowledge) using verbal and non-verbal interactions, wants the students to establish common ground by themselves. Lolly-stick stability and triangle stability are two things that the teachers try to establish common ground about. The didactical move the teacher uses in these situations seems to be intended to challenge the students to find out for themselves; the question is whether common ground is established or not. The teacher leaves them but comes back to the group several times during the lesson and asks questions about the stability of the lolly stick.
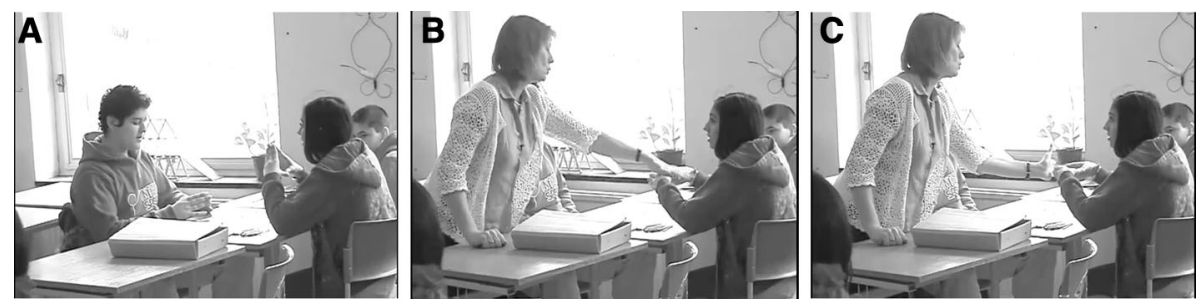

Fig. 4 Student showing the form of a triangle with her hands (a) and teacher asking in which direction it is best to load a triangle $(\mathbf{b}, \mathbf{c})$ 


\section{Didactical moves: joint affordances}

The teacher's didactical moves are directed towards establishing "new habits of thoughts". "A thought style is not only a set of common thoughts; it is a way of perceiving" (Sensevy 2011, p. 66). When common ground is established, we see the same objects/concepts in the same way; they provide some specific affordances. Moreover, teachers' didactical moves try to create joint affordances, meaning that students 'are led' to see what the object/knowledge/skills afford in the situation. The concept of affordances relates to possibilities as well as constraints of objects, processes and concepts within the situation. Awareness of the requirements of technical solutions is part of technology knowledge and the teacher stresses that the bridge specifications are important when building a bridge model, in order to establish joint affordances with regard to this.

\section{Lolly sticks as building material}

During a practical problem-solving activity in technology, joint affordances needs to be established both concerning the doing (procedural) and the knowing (conceptual). The teacher wants to establish joint affordances concerning the properties of the lolly stick (conceptual knowledge) by challenging the students to investigate properties of stability, as we can see in following excerpt:

3.11. Teacher: Yes in which direction are the lolly sticks strongest?

3.12. Student B: I don't know

3.13. Teacher: Like this or like this (turns the lolly stick on its side and then flat, see Fig. 5a, b)

3.14. Student B: I think it is like this (lolly stick lying flat, see Fig. 5b)... because

3.15. Teacher: Yes if you try to break the lolly stick...

3.16. Student B: Well...

3.17. Teacher: Like this or like this (turns the lolly stick in both directions, Fig. 5a, b)

3.18. Student B: Yes, like this... aha (holds the lolly stick as shown in Fig. 5a)

Student B first has a preconception of what is right (Fig. 5b). The didactical move that the teacher makes when interacting with the material allows Student B to see what the material affords. We interpret this situation as implying that the teacher wants the students to be aware of 'lolly stick properties', in order to establish some joint affordances concerning the possibilities for using lolly sticks in their construction. This can be interpreted as a move towards establishing conceptual knowledge. In other words, the teacher makes a move directed towards one of the basic entities (lolly stick).

After this lesson, the students have established fairly strong conceptions of the affordances of the lolly stick and the triangle. These conceptions are however, not connected to

Fig. 5 Reconstructed photo showing the lolly stick on its side (a) or lying flat (b) when discussing how to break a lolly stick most easily

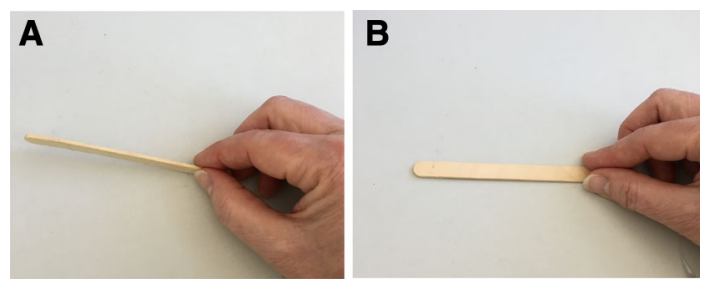


each other nor to the specific situation. If there were a firm connection between the affordance of lollies stick and the triangle, the students would have made triangles out of lollies sticks on their edge rather flat (see Fig. 6). Joint affordances are established regarding the procedure for building the bridge model and the material for doing that (procedural). There are joint affordances concerning concepts but they are not applied in the specific situation.

In Table 2, we sum up the various didactical moves this teacher makes concerning procedural and conceptual knowledge in relation to JATD.

\section{Discussion}

In this study, we have explored using JATD a teacher's interactions with students and milieu in practical problem-solving activities. To establish joint action between the teacher and the student-milieu, the teacher makes didactical moves, which we see as part of the implementation of relevant strategies to provide opportunities for facilitating students' learning of content.

The teacher makes several successful didactical moves to establish joint attention. When the teacher directs students towards the specific conditions for the bridge model, she establishes joint affordances and common ground concerning the construction as a whole. Students start discussing and building directly after the teacher's introduction, which focuses on bridge specifications such as the bridge length and span. In other words, the students have grasped the main idea, to build a bridge model. However, the consequence of this is that students build without any particular awareness of the stability of the lolly-stick triangle. The teacher lets the students investigate the material first, then (in Excerpt 1) she 'directs' them, in her endeavour to establish common ground regarding the properties of a lolly-stick and the stability of a triangle. In making this choice, the teacher ends up 'interfering' with the students long after they have started building. We ask whether it would have been more feasible to let the students investigate properties of the material (lolly sticks) and constructions with lolly-stick triangles first, to find out how to make a strong and stable construction for bridge building. As we interpret it, the didactical moves for joint affordances and common ground with regard to vital procedural and conceptual knowledge are not equally successful.

We find that the teacher establishes joint affordances and common ground about technological concepts by making didactical moves with regard to how the students can investigate the properties of the lolly stick and how the triangle form can withstand more pressure. However, there is a lack of didactical moves that might help the students to

Fig. 6 The bridge model made by the group in focus

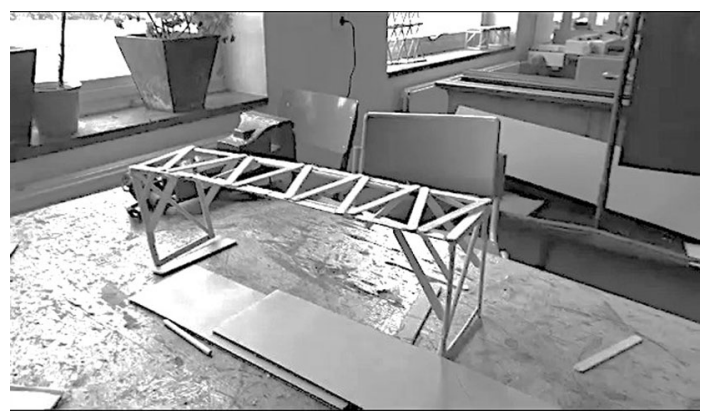


Table 2 Summing up the teacher's didactical moves

\begin{tabular}{|c|c|c|c|}
\hline & Joint attention & Common ground & Joint affordances \\
\hline \multicolumn{4}{|c|}{ Teacher's didactical moves } \\
\hline $\begin{array}{l}\text { Procedural } \\
\text { knowledge }\end{array}$ & $\begin{array}{l}\text { Repeated redirections of } \\
\text { students' attention } \\
\text { towards the limited } \\
\text { amount of material to } \\
\text { make them aware of } \\
\text { resources }\end{array}$ & $\begin{array}{l}\text { Challenging the students to } \\
\text { establish common ground } \\
\text { by themselves regarding } \\
\text { how to use stability when } \\
\text { building }\end{array}$ & $\begin{array}{l}\text { Making the students aware } \\
\text { of the limited amount of } \\
\text { material for building }\end{array}$ \\
\hline $\begin{array}{l}\text { Conceptual } \\
\text { knowledge }\end{array}$ & $\begin{array}{l}\text { Interrupting by asking } \\
\text { questions to redirect } \\
\text { students' attention } \\
\text { towards properties and } \\
\text { stability to make them } \\
\text { aware of knowledge that } \\
\text { is important }\end{array}$ & $\begin{array}{l}\text { Asking questions and } \\
\text { showing the students with } \\
\text { gestures how to } \\
\text { investigate and establish } \\
\text { common ground about } \\
\text { stability }\end{array}$ & $\begin{array}{l}\text { Asking questions about } \\
\text { properties and stability of } \\
\text { lolly-stick triangles to } \\
\text { make students see what } \\
\text { the material affords }\end{array}$ \\
\hline
\end{tabular}

integrate this knowledge with knowledge about building, i.e. procedural knowledge. The teacher's didactical move is directed towards establishing common ground about the stability of triangles, but after doing that she leaves it up to the students to integrate this knowledge about stability into the process of building a bridge model. When solving a practical problem in technology, the milieu can be described as the knowledge surroundings that provide opportunities for an integration of conceptual and procedural knowledge (de Vries 2005; McCormick 2004). When the teacher interacts with the studentmilieu, she tries to establish joint affordances and common ground in relation to both knowledge areas but only partially succeeds. The teacher's didactical moves do not provide enough support for students to achieve the learning goal regarding technology knowledge, which may be due to the gap between the students' conceptual and procedural knowledge. There may also be a lack of knowledge among teachers about how to integrate conceptual and procedural knowledge in a practical problem-solving activity, as well as a lack of understanding of such gaps among students. This knowledge is, however, demanding both to learn and to teach as technology solutions are context dependent (McCormick 2004).

Technological knowledge is also described as non-verbal (de Vries 2005). This nonverbal knowledge is part of the milieu and becomes visible in the interaction between teacher and student-milieu in this study. When joint attention is established, the teacher and students use gestures and the material, lolly sticks, to demonstrate their ideas without verbalising what and how they think. When the teacher makes a didactical move to establish joint affordances about the stability of lolly sticks, rather than verbally explaining, she wants the students to feel in which position the lolly stick is strongest by trying to break it. In this specific situation, it is important for the students to feel the properties of the lolly sticks so that they can implement these principles when building the bridge. The teacher's didactical moves for establishing joint affordances are mainly non-verbal. In school, verbal communication is the norm for sharing and explaining, but in technology, there is also a nonverbal knowledge that is difficult to communicate without experiencing with multiple senses (de Vries 2005). This implies the importance of didactical moves that give all students the opportunity to experience vital non-verbal knowledge.

In situations where students are struggling with both procedural and conceptual problems, one might perhaps think that there would be a need for the teacher to make didactical moves to sustain students' attention, i.e. that the teacher more actively uses the students' 
discussion as a starting point to explore these problems. We are not able to identify such moves in our limited material. Furthermore, based on the fact that this particular bridge model failed the test (to carry a weight of five kilograms), as was the case with several other student groups, we consider that the teacher should have made additional didactical moves in order to facilitate conceptual and procedural knowledge in this important initial phase of the work.

Awareness about didactical moves is an appropriate approach to better describe and understand how teachers implement their strategies when working with practical problemsolving activities in technology education. Furthermore, we also see didactical moves as a relevant tool for teachers when planning practical problem-solving activities in technology, which supports Sensevy's suggestion that JATD can have a prescriptive function. Thus, we argue that steps in teachers' strategies for facilitating students' learning might be concretised as didactical moves.

Open Access This article is distributed under the terms of the Creative Commons Attribution 4.0 International License (http://creativecommons.org/licenses/by/4.0/), which permits unrestricted use, distribution, and reproduction in any medium, provided you give appropriate credit to the original author(s) and the source, provide a link to the Creative Commons license, and indicate if changes were made.

\section{References}

Blomdahl, E., \& Rogala, W. (2008). Technology in compulsory school-Why? What? How? Design and Technology Education: An International Journal, 13(1), 19-28.

Brousseau, G. (1997). Theory of didactical situations in mathematics. Dordrecht: Kluwer.

Chevallard, Y., \& Sensevy, G. (2014). Anthropological approaches in mathematics education, French perspectives. In Encyclopedia of mathematics education (pp. 38-43). Dordrecht: Springer.

De Vries, M. (2005). Teaching about technology, an introduction to the philosophy of technology for nonphilosophers. Dordrecht: Springer.

Esjeholm, B. T., \& Bungum, B. (2013). Design knowledge and teacher-student interactions in an inventive construction task. International Journal of Technology and Design Education, 23(3), 675-689.

Ginestié, J. (2002). The industrial project method in French industry and in French schools. International Journal of Technology and Design Education, 12(2), 99-122.

Hansson, S. O. (2013). What is technological knowledge? In I.-B. Skogh \& M. J. de Vries (Eds.), Technology teachers as researchers (pp. 17-31). Rotterdam: SensePublishers.

Hill, A. M. (1998). Problem solving in real-life contexts: An alternative for design in technology education. International Journal of Technology and Design Education, 8(3), 203-220.

Hsieh, H. F., \& Shannon, S. E. (2005). Three approaches to qualitative content analysis. Qualitative Health Research, 15(9), 1277-1288.

Jones, A., Buntting, C., \& de Vries, M. (2011). The developing field of technology education: A review to look forward. International Journal of Technology and Design Education, 23(2), 191-212.

Laborde, C. (2015). Didactical situation. In R. Gunstone (Ed.), Encyclopedia of science education (Vol. 1, pp. 321-325). Berlin: Springer.

McCormick, R. (2004). Issues of learning and knowledge in technology education. International Journal of Technology and Design Education, 14(1), 21-44.

McCormick, R. (2006). Technology and knowledge: Contributions from learning theories. In Dakers (Ed.), Defining technological literacy: Towards an epistemological framework (Vol. 1, pp. 31-47). New York: Palgrave Macmillan.

Mitcham, C. (1994). Thinking through Technology. Chicago: The University of Chicago Press.

Pirttimaa, M., Husu, J., \& Metsärinne, M. (2015). Uncovering procedural knowledge in craft, design, and technology education: A case of hands-on activities in electronics. International Journal of Technology and Design Education, 25(1), 1-17.

Ropohl, G. (1997). Knowledge types in technology. International Journal of Technology and Design Education, 7(1-2), 65-72.

Ryle, G. (1949/2000). The concept of mind. London: Penguin Books. (Original work published 1949). 
Schoenfeld, A. H. (2012). Problematizing the didactical triangle. ZDM Mathematics Education, 44, 587-599.

Sensevy, G. (2011). Overcoming fragmentation: Toward a joint action theory in didactics. In B. Hudson \& M. Meyer (Eds.), Beyond fragmentation: Didactics, learning and teaching in Europe. Berlin: Budrich. Sensevy, G. (2012). About the joint action theory in didactics. Zeitschrift für Erziehungswissenschaft, 15(3), 503-516.

Sensevy, G. (2015). Milieu. In R. Gunstone (Ed.), Encyclopedia of science education. Dordrecht: Springer.

Skolverket. (2011). Läroplan för grundskolan, förskoleklassen och fritidshemmet 2011 [Curriculum for the compulsory school 2011]. Stockholm: Skolverket.

Venturini, P., \& Amade-Escot, C. (2014). Analysis of conditions leading to a productive disciplinary engagement during a physics lesson in a disadvantaged area school. International Journal of Educational Research, 64, 170-183.

Vincenti, W. G. (1990). What engineers know and how they know it: Analytical studies from aeronautical engineering. Baltimore: John Hopkins University Press.

Wittgenstein, L. (1953). Philosophical investigations (G. E. M. Anscombe, Trans.). 